\title{
PHBV/PCL Microparticles for Controlled Release of Resveratrol: Physicochemical Characterization, Antioxidant Potential, and Effect on Hemolysis of Human Erythrocytes
}

\author{
Jessica Bitencourt Emilio Mendes, ${ }^{1}$ Manoela Klüppel Riekes, ${ }^{2}$ Viviane Matoso de Oliveira, ${ }^{3}$ \\ Milton Domingos Michel, ${ }^{4}$ Hellen Karine Stulzer, ${ }^{2}$ Najeh Maissar Khalil, ${ }^{3}$ \\ Sônia Faria Zawadzki, ${ }^{5}$ Rubiana Mara Mainardes, ${ }^{3}$ and Paulo Vitor Farago ${ }^{1}$ \\ ${ }^{1}$ Postgraduate Program in Pharmaceutical Sciences, Department of Pharmaceutical Sciences, State University of Ponta Grossa, \\ 4748 Carlos Cavalcanti Avenue, 84030-900 Ponta Grossa, Brazil \\ ${ }^{2}$ Laboratory of Quality Control, Department of Pharmaceutical Sciences, Federal University of Santa Catarina, P.O. Box 476, \\ 88040-900 Florianópolis, Brazil \\ ${ }^{3}$ Laboratory of Nanotechnology, Department of Pharmacy, State University of the Center-West, 3 Simeão Camargo Varela de Sá St, \\ 85040-080 Guarapuava, Brazil \\ ${ }^{4}$ Department of Materials Engineering, State University of Ponta Grossa, 4748 Carlos Cavalcanti Avenue, \\ 84030-900 Ponta Grossa, Brazil \\ ${ }^{5}$ Department of Chemistry, Federal University of Paraná, P.O. Box 19081, 81531-990 Curitiba, Brazil
}

Correspondence should be addressed to Paulo Vitor Farago, pvfarago@gmail.com

Received 30 October 2011; Accepted 30 November 2011

Academic Editor: Gian Maria Pacifici

Copyright () 2012 Jessica Bitencourt Emilio Mendes et al. This is an open access article distributed under the Creative Commons Attribution License, which permits unrestricted use, distribution, and reproduction in any medium, provided the original work is properly cited.

\begin{abstract}
Microparticles of poly(3-hydroxybutyrate-co-3-hydroxyvalerate) (PHBV) and poly( $\varepsilon$-caprolactone) (PCL) containing resveratrol were successfully prepared by simple emulsion/solvent evaporation. All formulations showed suitable encapsulation efficiency values higher than $80 \%$. PHBV microparticles revealed spherical shape with rough surface and presence of pores. PCL microparticles were spherically shaped with smooth surface. Fourier-transformed infrared spectra demonstrated no chemical bond between resveratrol and polymers. X-ray powder diffraction patterns and differential scanning calorimetry analyses indicated that microencapsulation led to drug amorphization. These PHBV/PCL microparticles delayed the dissolution profile of resveratrol. Release profiles were better fitted to biexponential equation. The hypochlorous-acid-scavenging activity and 2,2azinobis(3-ethylbenzothiazoline-6-sulfonic acid) radical cation discoloration assay confirmed that the antioxidant activity of PHBV/PCL microparticles was kept, but was dependent on the microparticle morphology and dissolution profile. Resveratrolloaded PHBV/PCL microparticles showed no cytotoxic effect on red blood cells.
\end{abstract}

\section{Introduction}

Oxidative damage occurs as an outcome of an imbalance between the formation and inactivation of oxygen free radicals and has a potential to have deleterious effects [1]. Oxidative stress is included as a main cause of several chronic human diseases as cancer, diabetes, hypertension, cardiovascular diseases, and aging [2]. The superoxide anion $\left(\mathrm{O}_{2}{ }^{-}\right)$, hydrogen peroxide $\left(\mathrm{H}_{2} \mathrm{O}_{2}\right)$, and hydroxyl radical $\left(\mathrm{OH}^{*}\right)$ are some of the reactive oxygen species (ROS) and can produce (a) damage to cell membranes or other lipid structures mostly by lipid peroxidation of unsaturated fatty acids, (b) change in proteins by altering the tertiary structure and leading to loss of function, fragmentation, and crosslinking, and (c) changes in DNA which can be rearranged by repair mechanisms or may induce mutations $[1,3]$.

Currently, there is a great interest in antioxidants mainly due to the findings on the remarkable effects of free radicals in the human body. During an oxidative stress, the excess of free radicals can be counteracted by antioxidants produced 


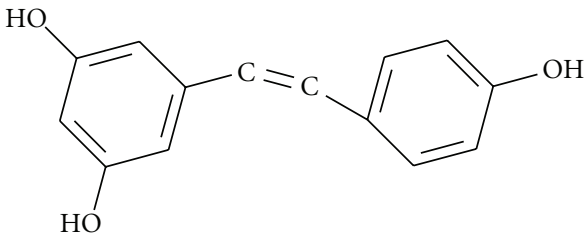

Figure 1: Chemical structure of resveratrol.

endogenously or absorbed through the diet [4]. Considering this perspective, resveratrol or trans-3,5,4'-trihydroxy-transstilbene (Figure 1) is a phytoalexin produced by plants in response to exogenous stress factors, such as injury, fungal infections, or UV irradiation. It has been shown to be a potent antioxidant, anti-inflammatory, anticancer, and chemoprotective agent. It is reported that the possible mechanisms for its various pharmacological activities involve modulating lipid metabolism, platelet aggregation, and inflammatory response [5-9]. The properties of resveratrol are attributed to its ability to inhibit low-density lipoprotein oxidation, while suppressing the activity of cyclooxygenase 2 and induced nitric oxide synthase also contributes to the anti-inflammatory and antioxidant effects [10]. This compound can particularly affect the process of carcinogenesis in its three stages: initiation, promotion, and progression. This drug has proved to be a suppressor of angiogenesis and metastasis of tumors [11-14].

Despite the numerous studies on the in vitro properties of polyphenolic compounds, their suitable effects are often not observed in vivo. This difference can be partially attributed to a low absorption and a high metabolism of these compounds that lead to a reduced in vivo result by oral administration as compared to their great in vitro efficacy [15]. Regarding the resveratrol, its polyphenolic structure shows high hydrophobicity and it is sensitive to some external agents such as air, light, and oxidative enzymes that can induce oxidation and a light-induced conversion from the trans $(\mathrm{Z})$ to the cis (E) isomer and can reduce its viability and bioavailability for clinical use [16-18].

Some recent papers are devoted to investigate resveratrolloaded micro-/nanoparticles in order to provide a controlled release or to improve its stability and bioavailability. Calcium-pectinate beads containing resveratrol were prepared and showed a delayed release and a site-specific delivery to the lower gastrointestinal tract [11]. Experimental parameters were studied to obtain resveratrol-loaded poly( $\varepsilon$-caprolactone $)$ nanoparticles with higher encapsulation efficiency and lower particle sizes by oil-in-water emulsion/solvent evaporation method [16]. Inclusion complexes between trans-resveratrol and $\beta$-cyclodextrin or hydroxypropyl- $\beta$-cyclodextrin revealed improved solubility and kept the scavenging capacity against the stable radical $\mathrm{DPPH}^{\circ}$ [19]. Resveratrol-loaded lipid-core nanocapsules increased the concentration of trans-resveratrol in the brain tissue and can be used for several brain diseases including Alzheimer's disease [20]. Pharmacokinetic studies of resveratrol-loaded nanoparticles were performed and demonstrated an increased systemic bioavailability [21].
Vanillin cross-linked chitosan microparticles showed a controlled release of resveratrol [22].

Inspite of these papers, the literature does not report studies involving resveratrol-loaded microparticles obtained from poly(3-hydroxybutyrate-co-3-hydroxyvalerate) (PHBV) and poly ( $\varepsilon$-caprolactone) (PCL) as polymers. These polyesters are attractive materials for controlledrelease drug applications due to their biodegradability. Their decomposition products are not toxic and are easily excreted [23]. Moreover, a lack of data is available regarding the effect of resveratrol-loaded microparticles on hemolysis of red blood cells. Thus, the aim of this paper was to obtain resveratrol-loaded PHBV/PCL microparticles by simple emulsion/solvent evaporation method and to evaluate their erythrocyte cytotoxicity using the hemolysis assay in order to investigate the feasibility of applying these polyester microparticles as an oral drug delivery carrier for controlled release.

\section{Materials and Methods}

2.1. Materials. trans-resveratrol $(99.8 \%$ pure, Pharma Nostra, Rio de Janeiro, Brazil), poly(3-hidroxybutirateco-3-hidroxyvalerate) (PHBV) $\left(\overline{M_{w}}=380,000 \mathrm{~g} \cdot \mathrm{mol}^{-1}\right.$, $8.70 \mathrm{~mol} \%$ hydroxyvalerate, Biocycle L110, PHB Industrial, Serrana, Brazil), poly(E-caprolactone) (PCL) $\left(\overline{M_{w}}=70,000\right.$ $90,000 \mathrm{~g} \cdot \mathrm{mol}^{-1}$, Sigma-Aldrich, St. Louis, MO, USA), and poly(vinyl alcohol) (PVA) $\left(\overline{M_{w}}=72,000 \mathrm{~g} \cdot \mathrm{mol}^{-1}, 88.5 \mathrm{~mol} \%\right.$ of hydrolysis, Vetec, Rio de Janeiro, Brazil) were used as received. The other reagents and solvents were of analytical grade.

\subsection{Preparation of Resveratrol-Loaded PHBV/PCL Micropar-} ticles. The polyester microparticles containing resveratrol were prepared by simple emulsion/solvent evaporation procedure [23]. Three different formulations (Table 1) were obtained for each polymer (PHBV/PCL) depending on the amount of resveratrol into their compositions $(5,10$, and $20 \%)$. Chloroform and methylene chloride were used as polymer solvent for PHBV and PCL, respectively. Briefly, the organic phase was added into the aqueous phase under mechanical stirring $\left(5.000 \mathrm{rev} \cdot \mathrm{min}^{-1}\right)$ for $5 \mathrm{~min}$. The emulsion was kept under mechanical stirring $\left(800 \mathrm{rev} \cdot \mathrm{min}^{-1}\right)$ at room temperature for $4 \mathrm{~h}$. After evaporation of organic solvent, microparticles were separated by centrifugation $\left(2.500 \mathrm{rev} \cdot \mathrm{min}^{-1}, 10 \mathrm{~min}\right)$, washed twice with purified water and dried under vacuum at $35 \pm 2^{\circ} \mathrm{C}$ for $4 \mathrm{~h}$. The samples were stored into a desiccator under vacuum at room temperature. All formulations were obtained in triplicate. Unloaded microparticles were also prepared as negative controls.

2.3. Residual Moisture. The water content of resveratrol, PHBV, PCL, and microparticles was performed using an infrared moisture analyzer (Top 160 Ray, Bel engineering, Monza, Italy). For each sample, an amount of $1.000 \mathrm{~g}$ was placed on an aluminum plate and dried at $105^{\circ} \mathrm{C}$ until constant weight. The percentage corresponding to mass loss was obtained as moisture content. The tests were carried out in triplicate. 
TABLE 1: Composition of resveratrol-loaded PHBV/PCL microparticles.

\begin{tabular}{lcccc}
\hline Composition & & & Formulation & \\
& R0 & R5 & R10 & R20 \\
\hline Aqueous phase & & & & \\
Polysorbate $80(\mathrm{~g})$ & 0.25 & 0.25 & 0.25 & 0.25 \\
PVA (g) & 4.00 & 4.00 & 4.00 & 4.00 \\
Purified water (mL) & 200.0 & 200.0 & 200.0 & 200.0 \\
Organic phase & & & & \\
Resveratrol (g) & - & 0.10 & 0.20 & 0.40 \\
PHBV (system M1) or PCL (system M2) (g) & 2.00 & 1.90 & 1.80 & 1.60 \\
Chloroform or methylene chloride (mL) & 40.0 & 40.0 & 40.0 & 40.0 \\
\hline
\end{tabular}

\subsection{Characterization}

2.4.1. Drug Loading and Encapsulation Efficiency. An amount of microparticles, equivalent to $20 \mathrm{mg}$ of resveratrol, was weighed and magnetic stirred $\left(1,000 \mathrm{rev} \cdot \mathrm{min}^{-1}\right)$ with $7 \mathrm{~mL}$ ethanol for $12 \mathrm{~h}$. The volume was completed to $10 \mathrm{~mL}$ and filtered through a poly(vinylidene fluoride) membrane filter (Durapore membrane, $0.22 \mu \mathrm{m}$ pore size, Millipore, Bedford, MA, USA). After suitable dilution in ethanol, the concentration of resveratrol was determined through HPLC system (Waters Alliance 2695 HPLC System, Milford, MA, USA) using a Waters XTerra C18 analytical column $(250 \times$ $4.6 \mathrm{~mm}, 5 \mu \mathrm{m}$ ) with UV detection at $306 \mathrm{~nm}$, in triplicate. The mobile phase consisted of $0.2 \%(\mathrm{v} / \mathrm{v})$ acetic acid in water, acetonitrile, and methanol $(2.3: 22.5: 75 \mathrm{v} / \mathrm{v})$. The validation of this HPLC method was previously performed through the following parameters: linearity, limit of detection, limit of quantitation, accuracy, robustness, precision, and specificity [24]. The concentration range varied from 10.0 to $50.0 \mu \mathrm{g} \cdot \mathrm{mL}^{-1}$. Linearity was 0.99981 , and the detection limit was $172.18 \mathrm{ng} \cdot \mathrm{mL}^{-1}$. The encapsulation efficiency (EE) was obtained using $(1)$

$$
\mathrm{EE}=\left(\frac{\text { mass of resveratrol in microparticles }}{\text { theoretical mass of resveratrol }}\right) \times 100 .
$$

2.4.2. Scanning Electron Microscopy (SEM). The samples were mounted on aluminum stubs, sputtered with gold (IC-50 Ion Coater, Shimadzu, Kyoto, Japan), and analyzed using a scanning electron microscope (SSX-550 Superscan, Shimadzu, Kyoto, Japan) at an accelerating voltage of 10 or $15 \mathrm{kV}$ with different magnifications.

2.4.3. Particle Size and Size Dispersion. The particle size and size dispersion of PHBV/PCL microparticles were measured by laser diffraction spectrometry (LDS) in a Cilas $920 \mathrm{~L}$ apparatus (Marseille, France). The dried powder samples were suspended in filtered water and sonicated into the ultrasonic bath coupled to the equipment for $1 \mathrm{~min}$ before measurements. Then, the mean diameters \pm standard deviations and the size distributions were determined. The span was calculated using

$$
\operatorname{span}=\frac{d_{(v, 90)}-d_{(v, 10)}}{d_{(v, 50)}},
$$

where $d_{(v, 10)}, d_{(v, 50)}$, and $d_{(v, 90)}$ are the particle diameters determined, respectively, at the 10th, 50th, and 90th percentile of the undersized particle distribution curve.

2.4.4. Fourier-Transformed Infrared Spectroscopy. The Fourier-transformed infrared (FTIR) spectra of raw materials, PHBV/PCL microparticles, and physical mixtures were recorded from 4000 to $400 \mathrm{~cm}^{-1}$ on a Shimadzu IR Prestige21 spectrophotometer (Kyoto, Japan) using $\mathrm{KBr}$ pellets with 32 scans and resolution of $4 \mathrm{~cm}^{-1}$.

2.4.5. X-Ray Powder Diffraction. Wide-angle X-ray powder diffraction (XRPD) was performed with a Shimadzu X-ray diffractometer (Shimadzu XRD-6000, Kyoto, Japan). The $2 \theta$ was increased from $5^{\circ}$ to $80^{\circ}$ at a scan rate of $2^{\circ} \cdot \mathrm{min}^{-1}$ using a Cu-K $\alpha$ source $(\lambda=1.5418 \AA)$ at $40 \mathrm{kV}$ and $40 \mathrm{~mA}$.

\subsubsection{Thermal Analyses}

Thermogravimetric Analysis (TG). The thermogravimetric curves were obtained in a thermobalance (TGA-50, Shimadzu, Kyoto, Japan) in the temperature range of 298$1173 \mathrm{~K}$ using platinum crucibles with $5.0 \pm 0.1 \mathrm{mg}$ of sample under dynamic $\mathrm{N}_{2}$ atmosphere (flow rate: $50 \mathrm{~mL} \cdot \mathrm{min}^{-1}$ ) and heat flow of $10 \mathrm{~K} \cdot \mathrm{min}^{-1}$. The equipment was previously calibrated with copper sulphate pentahydrate.

Differential Scanning Calorimetry (DSC). DSC curves of resveratrol, PHBV, PCL, physical mixtures, and microparticles were obtained in a DSC-60 calorimeter (Shimadzu, Kyoto, Japan) using aluminum crucibles with $2.5 \pm 0.1 \mathrm{mg}$ of sample under dynamic $\mathrm{N}_{2}$ atmosphere (flow rate: $50 \mathrm{~mL} \cdot \mathrm{min}^{-1}$ ). The temperature range was $298-773 \mathrm{~K}$ with heating rate of $10 \mathrm{~K} \cdot \mathrm{min}^{-1}$. An empty aluminum pan was used as reference. The DSC cell was calibrated with indium (m.p. $=429.6 \mathrm{~K} ; \Delta H_{\text {fusion }}=28.54 \mathrm{~J} \cdot \mathrm{g}^{-1}$ ) and zinc (m.p. $=$ $692.6 \mathrm{~K})$.

2.5. In Vitro Drug Release. In-vitro release was carried out for pure drug and resveratrol-loaded PHBV/PCL microparticles. Dissolution assays were performed in a Nova Ética dissolution tester (299/6, Vargem Grande Paulista, Brazil) equipped with paddles (apparatus II) in $900 \mathrm{~mL}$ of degassed 
TABLE 2: Mathematical models related to dissolution experiments.

\begin{tabular}{ll}
\hline Model & Equation \\
\hline Dissolution efficiency & $\mathrm{DE}=\left(\int_{0}^{t} y \cdot d t / y_{100} \cdot t\right) \times 100 \%$ \\
First-order & $\% D=100\left(1-e^{-k t}\right)$ \\
Biexponential & $\% D=100\left[1-\left(A e^{-\alpha t}+B e^{-\beta t}\right)\right]$ \\
Zero-order & $\% D=k t$ \\
Weibull & $\% D=100\left[1-e^{-(t / T D) b}\right]$ \\
\hline
\end{tabular}

Legend: $\% D$ : dissolved percentage, $b$ : shape parameter, $T D$ : time interval necessary to release $63.2 \%$ of the drug, $k, \alpha$ and $\beta$ : kinetics constants, $t$ : dissolution time, $A$ and $B$ : initial drug concentrations that contribute for the two dissolution stages.

phosphate buffer solution $\left(\mathrm{pH}=6.8,50 \mathrm{mmol} \cdot \mathrm{L}^{-1} \mathrm{KH}_{2} \mathrm{PO}_{4}\right.$ and $22.4 \mathrm{~mol} \cdot \mathrm{L}^{-1} \mathrm{NaOH}$ ) for $12 \mathrm{~h}$ in triplicate. System was kept at a thermostatically controlled temperature of $37 \pm$ $0.5^{\circ} \mathrm{C}$ and stirred at $75 \mathrm{rev} \cdot \mathrm{min}^{-1}$. All experiments were held under dark conditions. At predetermined time intervals, samples were collected $(10 \mathrm{~mL})$, filtered $(0.45 \mu \mathrm{m}$ pore size), and spectrophotometrically evaluated (Genesys $10 \mathrm{~S}$ spectrophotometer, Thermo Scientific, Madison, WI, USA) at $306 \mathrm{~nm}$. The dissolution value was obtained from the amount of drug released. A correction factor was applied to the cumulative dilution caused by replacement of the sample with an equal volume of fresh medium.

2.5.1. Analysis of Release Behavior. Dissolution profiles of resveratrol and PHBV/PCL microparticles were compared by independent and dependent methods as summarized in Table 2. As model-independent analysis, dissolution efficiency, the area under a dissolution curve between defined time points [25], was used. Profiles were also investigated by model-dependent methods using the MicroMath Scientist 2.01 software (Salt Lake City, UT, USA). Data were tested to fit first-order, biexponential, zero-order, and Weibull's equations (Table 2) [26]. The selection of model-dependent method was based on the best correlation coefficient $(r)$, the best model selection criteria (MSC), and the best graphic adjustment.

In order to have some insight into the drug release mechanism, a very simple and semiempirical equation to describe drug release from polymeric systems, the power law (Korsmeyer-Peppas model) [27], was also applied

$$
f t=a t^{n}
$$

where $f t$ is the drug dissolved fraction at time $t, n$ is the release exponent, indicative of the mechanism of the drug release, and $a$ is the constant incorporating structural and geometric characteristics of the drug dosage form.

2.6. Antioxidant Potential. In order to compare the antioxidant capacity of pure resveratrol and resveratrol-loaded microparticles, the antioxidant potential was evaluated by hypochlorous-acid- (HOCl-) scavenging assay and 2,2-azinobis(3-ethylbenzothiazoline-6-sulfonic acid) (ABTS) radical cation discoloration. Aqueous solutions of pure drug and loaded microparticles (M1R20/M2R20) containing the same concentrations of resveratrol were prepared $30 \mathrm{~min}$ before start of experiments and kept under dark conditions.

2.6.1. HOCl Scavenging Activity. After $5 \mathrm{~min}$ of reacting $75 \mu \mathrm{mol} \cdot \mathrm{L}^{-1} \mathrm{HOCl}(30 \mu \mathrm{L})$ with each aqueous solution $(20 \mu \mathrm{L})$ of pure drug or loaded microparticles (M1R20/M2R20), a volume of $20 \mu \mathrm{L}$ of a solution containing $10 \mathrm{mmol} \cdot \mathrm{L}^{-1} 3,3^{\prime}, 5,5^{\prime}$-tetramethylbenzidine (TMB) dissolved in $50 \%$ dimethylformamide, $100 \mu \mathrm{mol} \cdot \mathrm{L}^{-1}$ potassium iodide and $400 \mathrm{mmol} \cdot \mathrm{L}^{-1}$ acetic acid was added [28]. The reaction was performed in $50 \mathrm{mmol} \cdot \mathrm{L}^{-1}$ sodium phosphate buffer solution $(\mathrm{pH}=7.4)$ to a final volume of $200 \mu \mathrm{L}$ at $37^{\circ} \mathrm{C}$ for $15 \mathrm{~min}$. The absorbance was recorded at $650 \mathrm{~nm}$ in a microplate reader (SpectraMax 190 spectrophotometer, Molecular Devices, Sunnyvale, CA, USA). All measurements were performed in triplicate, and unloaded-microparticles (M1R0/M2R0) were used as negative control. The antioxidant activity was obtained as percentage of $\mathrm{HOCl}$ inhibition using

$$
\% \text { inhibition }=\left[\frac{(A b-A a)}{A b}\right] \times 100
$$

where $A b$ is the absorbance of the control and $A a$ is the absorbance of the sample.

2.6.2. ABTS Radical Cation Discoloration Assay. In brief, aqueous solutions of $7 \mathrm{mmol} \cdot \mathrm{L}^{-1} \mathrm{ABTS}$ and $2.45 \mathrm{mmol} \cdot \mathrm{L}^{-1}$ potassium persulfate were mixed in a volume ratio of $1: 1$ and incubated in dark at room temperature for $12 \mathrm{~h}$ to obtain ABTS $^{\bullet+}$ [29]. The ABTS $^{\bullet+}$ solution was diluted to an absorbance value of \pm 0.7 at $734 \mathrm{~nm}$ in $50 \mathrm{mmol} \cdot \mathrm{L}^{-1}$ sodium phosphate buffer solution $(\mathrm{pH}=7.4)$. The reduction between $\mathrm{ABTS}^{\bullet+}$ and pure drug or loaded microparticles (M1R20/M2R20) was measured by decreasing absorbance at $734 \mathrm{~nm}$ after $30 \mathrm{~min}$ in a microplate reader (SpectraMax 190 spectrophotometer, Molecular Devices, Sunnyvale, CA, USA). All measurements were performed in triplicate, and, unloaded microparticles (M1R0/M2R0) were used as negative control. The antioxidant activity was calculated as percentage of $\mathrm{ABTS}^{\bullet+}$ inhibition according to (4).

2.7. Erythrocyte Hemolysis Assay. The in vitro cytotoxic effect of pure resveratrol and PHBV/PCL microparticles was studied using heparinized venous blood samples collected from healthy volunteers. This experiment involving human blood was approved by the Ethics Committee of the State University of Ponta Grossa.

Fresh blood was centrifuged ( $4000 \mathrm{rev} \cdot \mathrm{min}^{-1}$ for $5 \mathrm{~min}$ ) at $4^{\circ} \mathrm{C}$ using a refrigerated centrifuge, and the plasma and buffy coat were carefully removed by aspiration. The red blood cells were washed three times by centrifugation ( $4000 \mathrm{rev} \cdot \mathrm{min}^{-1}$ for $5 \mathrm{~min}$ ) in cold phosphate buffer solution $\left(0.15 \mathrm{mmol} \cdot \mathrm{L}^{-1} \mathrm{NaCl}, 50 \mathrm{mmol} \cdot \mathrm{L}^{-1} \mathrm{NaH}_{2} \mathrm{PO}_{4} / \mathrm{Na}_{2} \mathrm{HPO}_{4}\right.$, $\mathrm{pH}=7.4$ ). The red blood cells were finally resuspended with the same buffer to obtain a hematocrit of 5\% [30].

Freshly prepared aqueous solutions $(10 \mu \mathrm{L})$ of pure drug or loaded microparticles (M1R20/M2R20) containing the same concentration of resveratrol $\left(71 \mu \mathrm{g} \cdot \mathrm{mL}^{-1}\right)$ were 
TABLE 3: Water content ${ }^{1}$, resveratrol entrapped into microparticles ${ }^{1}$, encapsulation efficiency (EE) ${ }^{2}$, particle size, and span for PHBV/PCL microparticles.

\begin{tabular}{|c|c|c|c|c|c|}
\hline Microparticles & Water content $(\%)$ & Resveratrol-loaded $\left(\mathrm{mg} \cdot \mathrm{g}^{-1}\right)$ & $\mathrm{EE}(\%)$ & Mean diameter $(\mu \mathrm{m})$ & Span \\
\hline M1R0 & $1.29 \pm 0.11$ & - & - & 25.23 & 2.38 \\
\hline M1R5 & $1.50 \pm 0.09$ & $46.43 \pm 1.77$ & 93 & 47.00 & 1.88 \\
\hline M1R10 & $1.10 \pm 0.08$ & $83.80 \pm 2.41$ & 84 & 33.75 & 2.25 \\
\hline M1R20 & $1.40 \pm 0.12$ & $159.30 \pm 2.72$ & 80 & 29.20 & 2.27 \\
\hline M2R0 & $1.57 \pm 0.13$ & - & - & 33.97 & 1.33 \\
\hline M2R5 & $1.56 \pm 0.11$ & $50.63 \pm 1.61$ & 101 & 52.09 & 1.27 \\
\hline $\mathrm{M} 2 \mathrm{R} 10$ & $1.09 \pm 0.08$ & $89.41 \pm 2.03$ & 89 & 52.84 & 1.37 \\
\hline M2R20 & $1.55 \pm 0.14$ & $176.70 \pm 2.55$ & 88 & 55.73 & 1.76 \\
\hline
\end{tabular}

${ }^{1}$ mean $(n=3) \pm$ standard deviation; ${ }^{2}$ mean $(n=3)$.

incubated in triplicate at $37^{\circ} \mathrm{C}$ with a $5 \%$ red blood cell suspension $(450 \mu \mathrm{L})$ and the previously prepared phosphate buffer solution $(40 \mu \mathrm{L})$ for $24 \mathrm{~h}$ under constant shaking at $120 \mathrm{rev} \cdot \mathrm{min}^{-1}$. The red blood cell suspension was then centrifuged at $4000 \mathrm{rev} \cdot \mathrm{min}^{-1}$ for $5 \mathrm{~min}$. Hemolysis was determined by measuring the absorbance at $540 \mathrm{~nm}$ in a microplate reader (SpectraMax 190 spectrophotometer, Molecular Devices, Sunnyvale, CA, USA) [31, 32]. Tests were also carried out for unloaded-microparticles (M1R0/M2R0). Hemolysis observed in the absence of sample was taken as blank. Groups were compared using one-way ANOVA followed by Tukey's post hoc test. A $P$ value of $\leq 0.05$ was used to indicate statistically significant differences.

\section{Results and Discussion}

The polyester microparticles were successfully prepared by simple emulsion/solvent evaporation method. After drying, PHBV microparticles (system M1) showed powder aspect and pale yellow color similar to PHBV. For PCL microparticles (system M2), powder aspect and off-white color were observed. Water contents of $1.20 \pm 0.12 \%, 3.59 \pm 0.17 \%$, and $1.12 \pm 0.09 \%$ were obtained for pure resveratrol, PHBV and PCL, respectively. Microparticles showed only residual moisture values as presented in Table 3. These data demonstrate that the performed vacuum drying was able to remove the water used during microencapsulation. The residual water content in a powder influences its physical stability and controls the magnitude of capillary forces that hold particles in aggregates [33]. Considering the obtained results, it is possible to establish that the water content exhibits little interference in the physical stability of PHBV/PCL microparticles.

3.1. Drug Loading and Encapsulation Efficiency. The drug content and encapsulation efficiency for the prepared microparticles are also summarized in Table 3. High percentages of drug entrapment were obtained for PHBV/PCL microparticles by simple emulsion/solvent evaporation. All formulations showed suitable EE values higher than $80 \%$. These values are mainly based on the poor aqueous solubility $\left(13.6 \mu \mathrm{g} \cdot \mathrm{g}^{-1}\right.$ in $\left.\mathrm{pH}=7.4\right)$ of resveratrol [34] which leads to an increase in the drug loaded into microparticles. Similar results were previously reported. A resveratrol entrapment higher than $97.7 \%$ was achieved for calcium-pectinate beads prepared by instantaneous gelation of pectin [11]. Resveratrol-loaded nanoparticles showed EE from 78.3 to $91.4 \%$ using PCL of $\overline{M_{w}}=65,000 \mathrm{~g} \cdot \mathrm{mol}^{-1}$ [16]. Vanillin cross-linked chitosan microparticles containing resveratrol revealed a drug entrapment higher than $93.7 \%$ [22].

The polymer: drug ratio is also a critical factor during microparticle formation and can influence EE values [35]. The enhancement of resveratrol entrapment was observed when the polyester amount was increased (Table 3). For PHBV microparticles, EE was increased from 80 to $93 \%$ as polymer:drug ratio was improved from 4:1 (20\% resveratrol) to $19: 1$ (5\% resveratrol). Resveratrol entrapment varied from 88 to $101 \%$ for PCL microparticles when polymer: drug ratio was changed at the same proportion. This effect can be simply due to the greater polymer with respect to the drug amount.

3.2. Scanning Electron Microscopy. The scanning electron micrographs of PHBV/PCL microparticles are shown in Figure 2. Different morphological aspects were observed depending on the polyester used. By SEM, PHBV microparticles were spherical shaped with a rough surface and pores (Figures 2(a)-2(d)). The presence of pores represents important morphological evidence that can change the drug release process from microparticles [36]. However, PCL microparticles revealed a spherical shape with smooth surface (Figures 2(e)-2(h)), and no pore were observed. Moreover, formulation M2R20 showed a residual resveratrol onto the microparticles surface. This external drug can be rapidly dissolved into an aqueous medium and provide an immediate-release behavior (burst effect) [23]. This effect has been also observed in other studies related to delayedrelease biopolymer systems $[37,38]$.

3.3. Particle Size and Size Dispersion. The particle size and size distribution obtained by LDS measurements are indicated in Table 3. Micrometer-sized particles with mean diameters less than $60 \mu \mathrm{m}$ were obtained. Although these particle sizes do not allow an uptake by intestinal tissue, the oral administration of these microparticles can provide sustained drug effect due to their prolonged bowel transit 


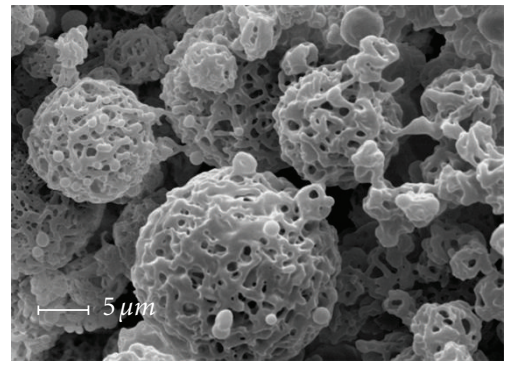

(a)

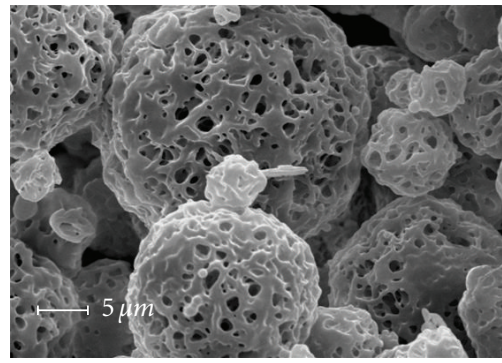

(d)

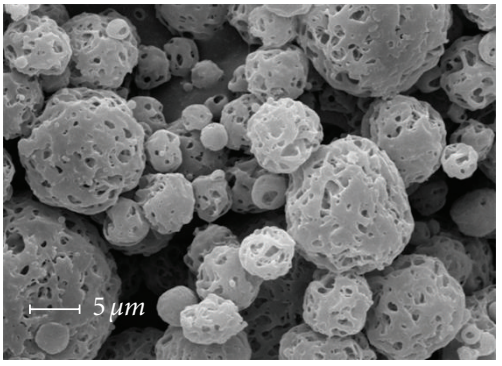

(b)

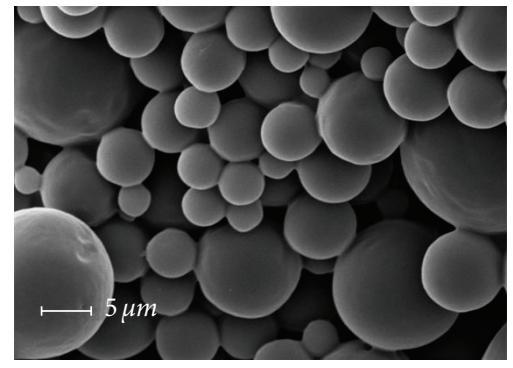

(e)

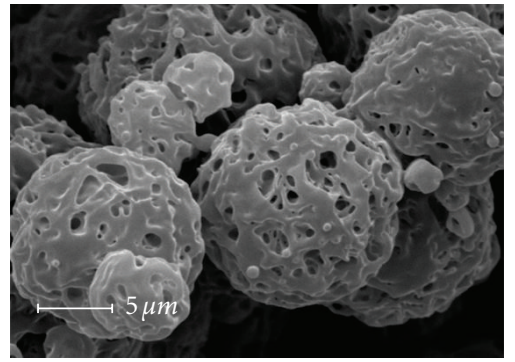

(c)

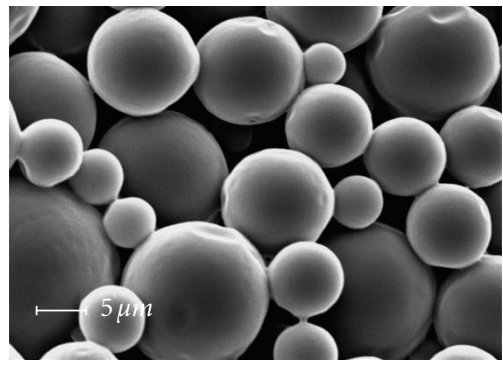

(f)

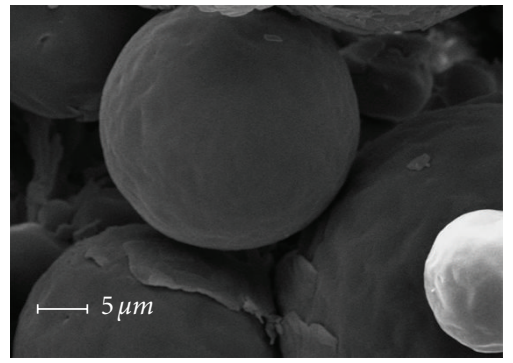

(g)

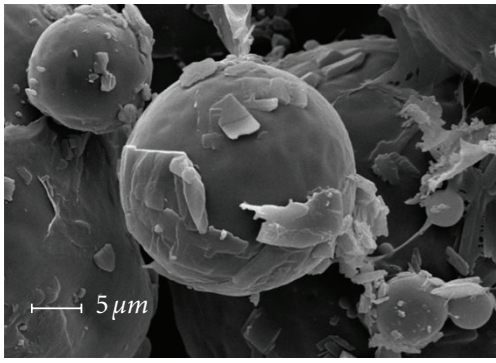

(h)

FIGURE 2: Scanning electron micrographs of PHBV/PCL microparticles: M1R0 (a), M1R5 (b), M1R10 (c), M1R20 (d), M2R0 (e), M2R5 (f), M2R10 (g), and M2R20 (h). Magnifications of 2000x.

time [39]. Regarding that a low span value indicates a narrow polydispersity [40], PCL microparticles presented a more homogeneous size distribution when compared to PHBV microparticles.

3.4. Fourier-Transformed Infrared Spectroscopy. FTIR spectra performed for resveratrol, PHBV, PCL, physical mixtures, and PHBV/PCL microparticles are shown in Figure 3. The FTIR spectrum of pure resveratrol showed a typical $\mathrm{OH}-$ stretching band at $3257 \mathrm{~cm}^{-1}$ and three intense bands at 1610,1589 , and $1385 \mathrm{~cm}^{-1}$ corresponding to $\mathrm{C}-\mathrm{C}$ aromatic double-bond stretching, $\mathrm{C}-\mathrm{C}$ olefinic stretching, and $\mathrm{C}-\mathrm{O}$ stretching. The typical trans olefinic band was observed at $965 \mathrm{~cm}^{-1}$ [5]. PHBV infrared spectrum exhibited a strong band at $1720 \mathrm{~cm}^{-1}$ due to $\mathrm{C}=\mathrm{O}$ stretching. Typical bands from 800 to $975 \mathrm{~cm}^{-1}$ corresponded to symmetric-C-O-Cstretching vibration. Moreover, the antisymmetric-C-O-Cstretching leads to bands between 1060 and $1150 \mathrm{~cm}^{-1}$ [35]. Considering PCL is also an aliphatic polyester, its spectrum is similar to that of PHBV with a strong band at $1727 \mathrm{~cm}^{-1}$ corresponding to $\mathrm{C}=\mathrm{O}$ stretching and two bands at 2943 and $2864 \mathrm{~cm}^{-1}$ due to symmetric and asymmetric $\mathrm{CH}_{2}$ stretching, respectively [41].

Physical mixtures and microparticles presented band assignments at the same wavenumber range of FTIR spectrum. Therefore, no difference in the positions of the absorption bands was observed between resveratrol-loaded microparticles and respective physical mixtures. Consequently, no chemical bond between drug and polymers was formed during microencapsulation.

3.5. X-Ray Powder Diffraction. Figure 4 shows the XRPD patterns of resveratrol, PHBV, PCL, physical mixtures, and PHBV/PCL microparticles. Pure resveratrol presented different peaks related to a crystalline structure, and its main peaks appear at $2 \theta=6.62,16.30,19.17,22.43$, 23.55, and 28.37. Resveratrol-loaded microparticles revealed XRPD patterns similar to pure PHBV/PCL and unloadedmicroparticles (M1R0/M2R0). These results suggest that the microencapsulation procedure provided a remarkable decrease of the crystalline diffraction peaks of resveratrol leading to drug amorphization [42]. 


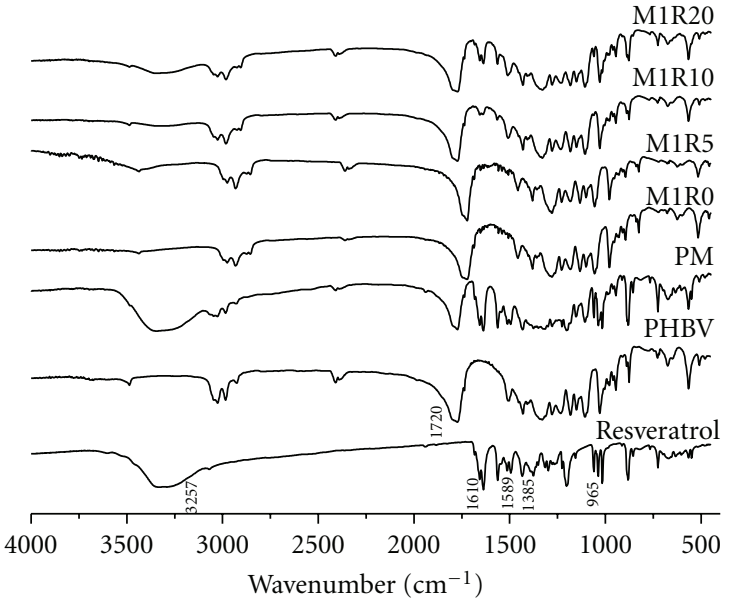

(a)

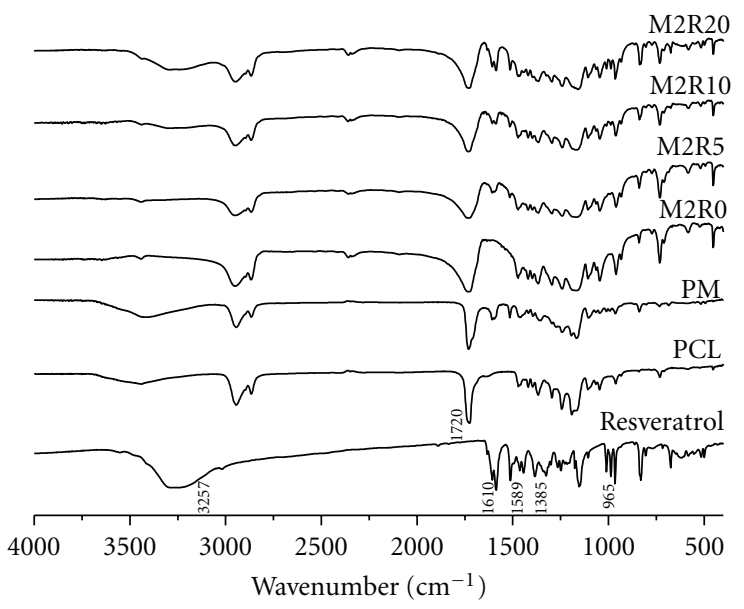

(b)

FIGURE 3: FTIR spectra of resveratrol, PHBV/PCL, physical mixtures, and PHBV/PCL microparticles.

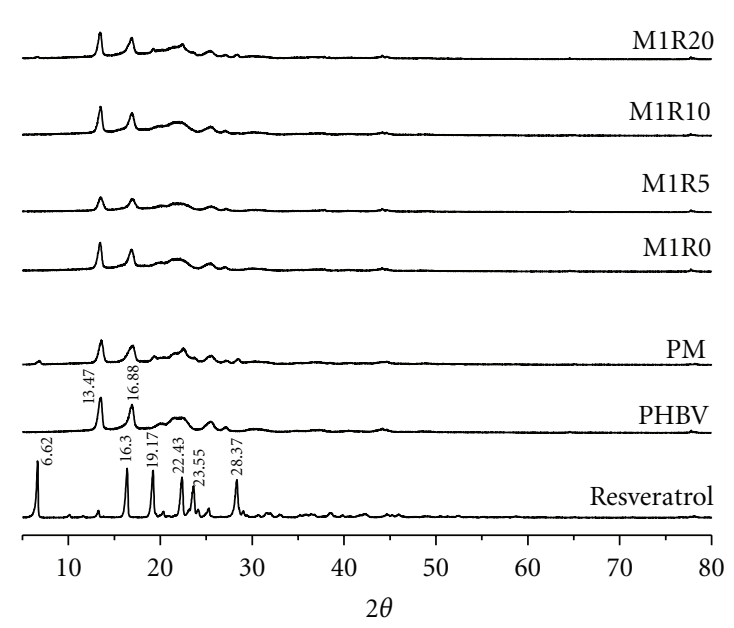

(a)

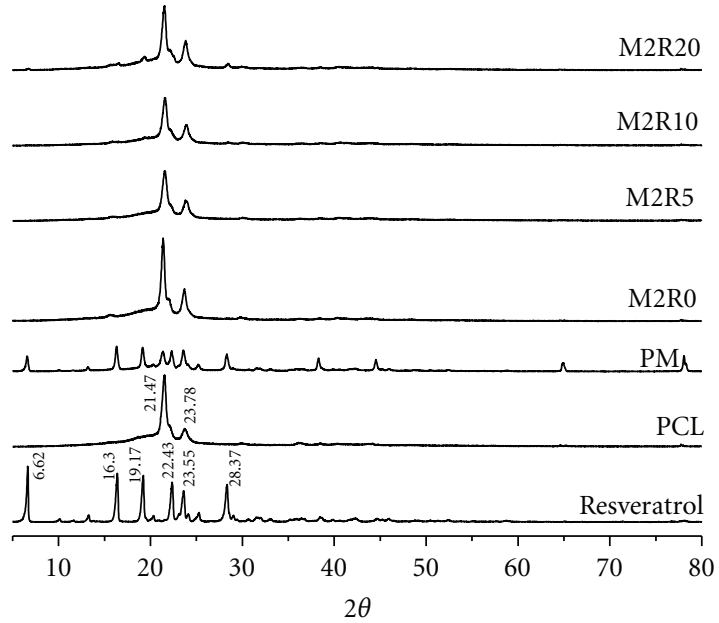

(b)

FIgURE 4: XRPD patterns of resveratrol, PHBV/PCL, physical mixtures, and PHBV/PCL microparticles.

Substances in solid state can reveal crystalline and/or amorphous characteristics. In general, amorphous solids are more soluble than crystalline forms due to free energies involved in the dissolution process. Solids in amorphous state have randomly arranged molecules, and thus low energy is required to separate them. Consequently their dissolution is faster than when in the crystal form [43].

\subsection{Thermal Analyses}

3.6.1. Thermogravimetric Analysis. The TG curves of pure resveratrol, PHBV, PCL, physical mixtures, and PHBV/PCL microparticles are shown in Figures 5 and 6. Resveratrol presented two events of weight loss that can be observed through its derivative thermogravimetric curve (DTG). The first event ranged from 625 to $758 \mathrm{~K}(\Delta m=41.7 \%)$, while the second one occurred between 758 and $1150 \mathrm{~K}(\Delta m=$ $57.5 \%)$. Both polymers showed only one event of weight loss,

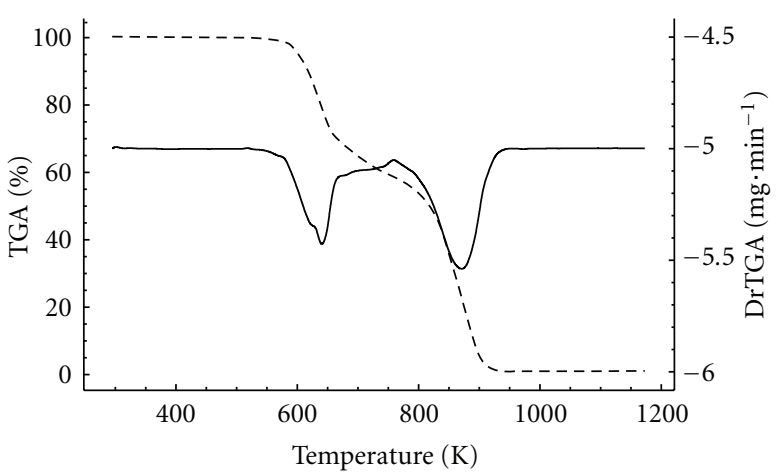

Figure 5: TG and DTG curves of resveratrol.

ranging from 564 to $591 \mathrm{~K}(\Delta m=97.6 \%)$ for $\mathrm{PHBV}$ and from 639 to $734 \mathrm{~K}(\Delta m=97.7 \%)$ for PCL.

PHBV microparticles demonstrated onset temperatures of degradation at 585,581, 577, and $582 \mathrm{~K}$ for M1R0, 


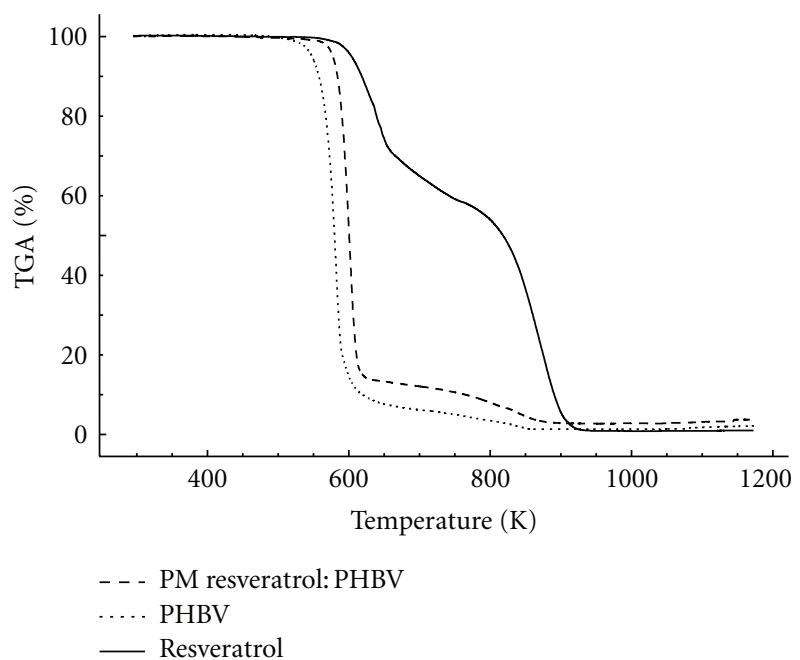

(a)

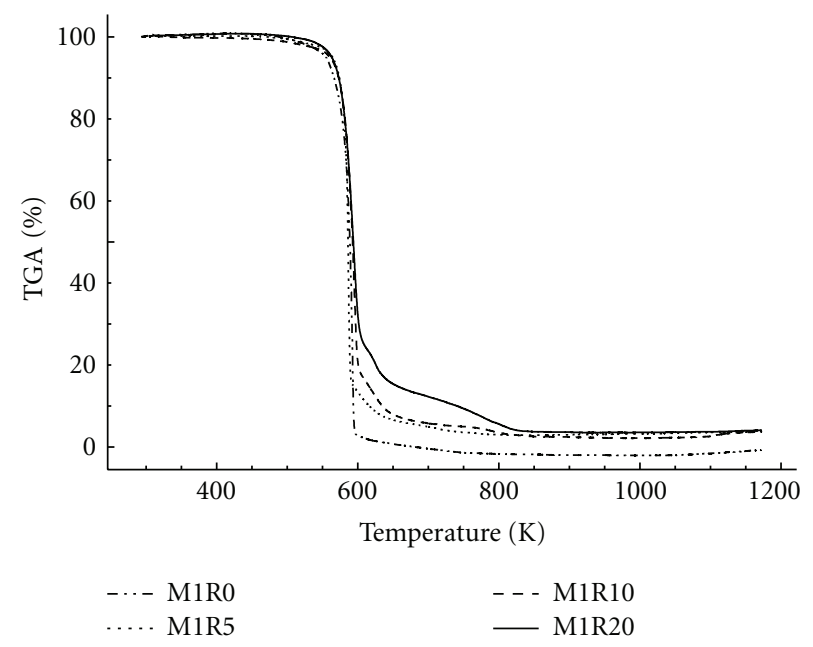

(c)

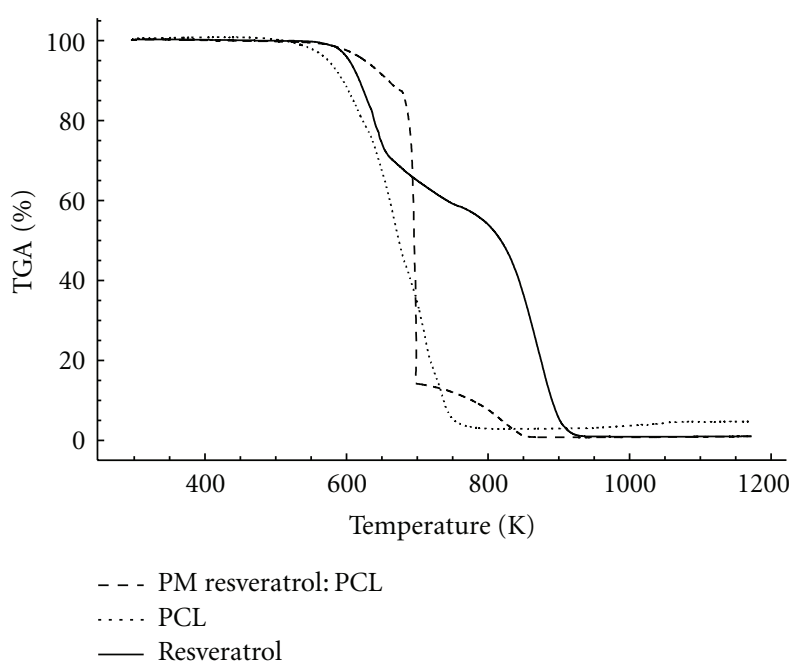

(b)

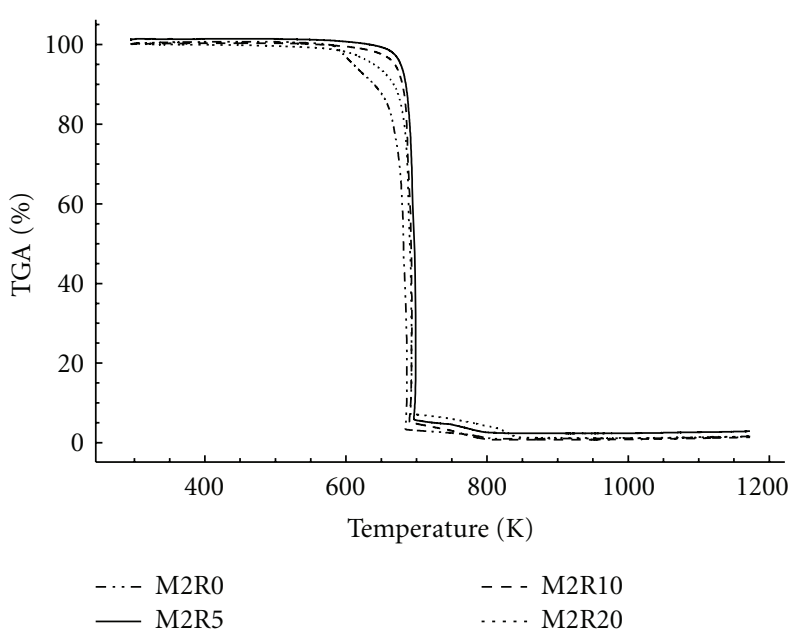

(d)

FIGURE 6: TG curves of resveratrol, PHBV/PCL and physical mixtures (a) and (b), PHBV microparticles (c), and PCL microparticles (d).

M1R5, M1R10, and M1R20, respectively. Otherwise PCL microparticles started their degradation at $671 \mathrm{~K}$ (M2R0), $689 \mathrm{~K}$ (M2R5), $686 \mathrm{~K}$ (M2R10), and $683 \mathrm{~K}$ (M2R20). These results indicate that PCL microparticles are thermally more stable than those composed by PHBV. Similar data were previously described for carvedilol-loaded microparticles, in which formulations containing PCL revealed increased thermal stability than formulations prepared with PHBV [23].

3.6.2. Differential Scanning Calorimetry. DSC curves of pure resveratrol, PHBV, PCL, physical mixtures, and PHBV/PCL microparticles are indicated in Figure 7. Resveratrol showed a sharp endothermic event at $539 \mathrm{~K}$ in accordance with the literature values $[44,45]$. The melting temperatures $\left(\mathrm{T}_{\mathrm{m}}\right)$ obtained for polymers were $438 \mathrm{~K}$ for PHBV and $333 \mathrm{~K}$ for PCL, confirming previously reported data [41].

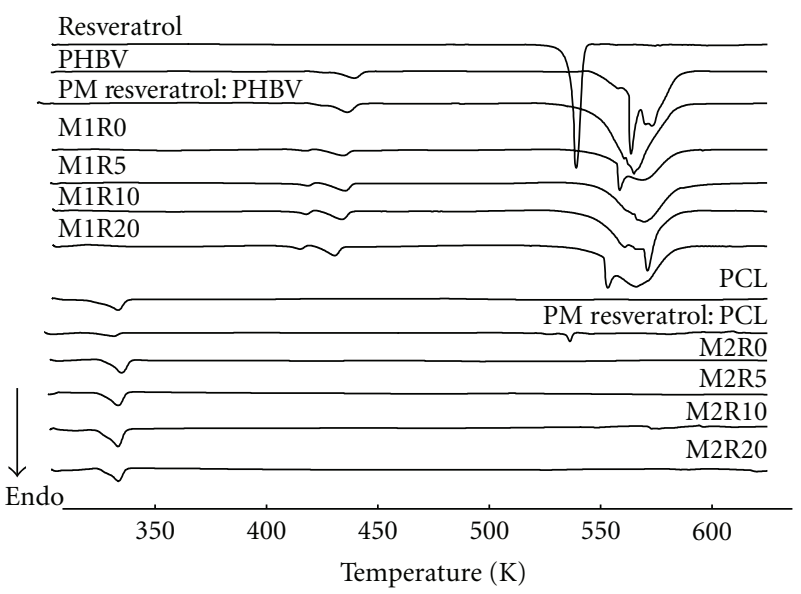

FIGURE 7: DSC curves of resveratrol, PHBV/PCL, physical mixtures, and PHBV/PCL microparticles. 

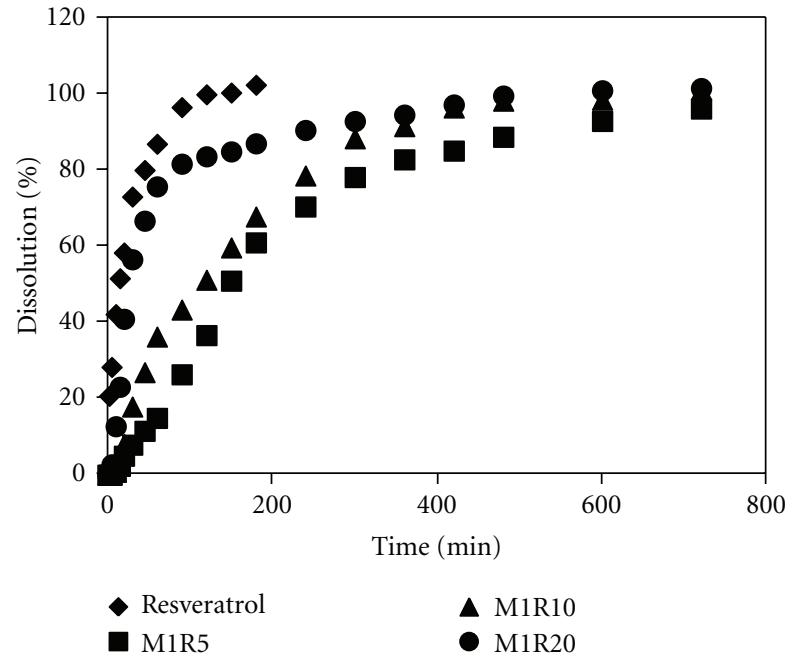

(a)

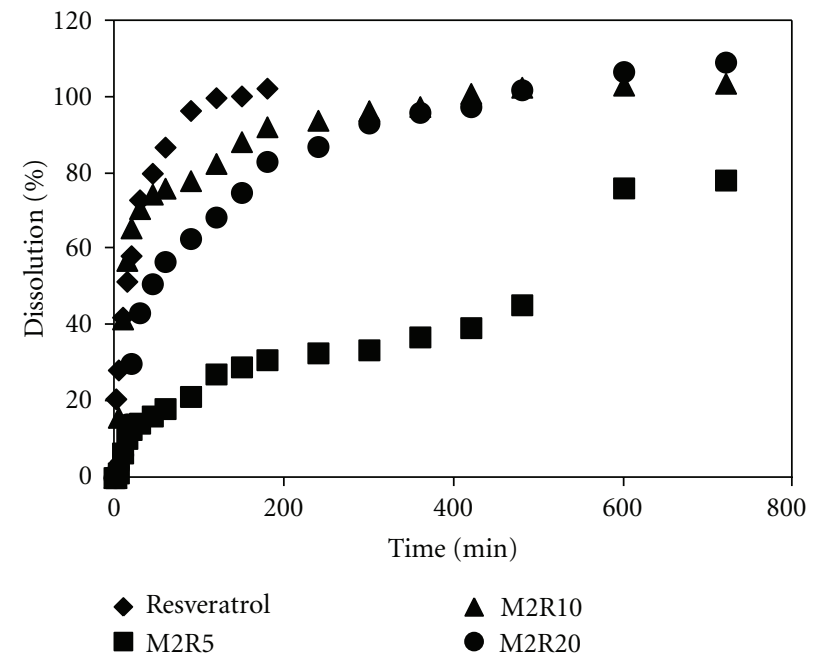

(b)

FiguRE 8: In vitro release profiles of pure drug and resveratrol-loaded PHBV/PCL microparticles.

The typical melting event of resveratrol was not observed in DSC curves of PHBV/PCL microparticles. This thermal behavior suggests that a drug amorphization occurred. This result is reinforced by the XRPD patterns of $\mathrm{PHBV} / \mathrm{PCL}$ microparticles in which only the characteristic crystalline peaks of the polymers were observed.

3.7. In Vitro Drug Release and Analysis of Release Behavior. The dissolution rates of resveratrol and PHBV/PCL microparticles are shown in Figure 8 . By the performed dissolution test, the mean time for $80 \%$ release of pure resveratrol was $45 \mathrm{~min}$. However, $\mathrm{PHBV}$ microparticles demonstrated mean dissolution times of $300 \mathrm{~min}$ (M1R5), $240 \mathrm{~min}$ (M1R10), and $90 \mathrm{~min}$ (M1R20) for $80 \%$ drug release. For PCL microparticles, a value of $80 \%$ drug release was achieved in mean dissolution times of 720, 300, and 180 min for M2R5, M2R10, and M2R20, respectively. Therefore resveratrol from PHBV/PCL microparticles showed a slower dissolution rate than pure drug.

These results demonstrate that PHBV/PCL played an important role on the delay of drug dissolution. This behavior can be related to polymer: drug ratio and morphological aspects. For both PHBV/PCL microparticles, formulations obtained at a polymer: drug ratio of 19:1 (5\% resveratrol) showed slower release of resveratrol. Probably the greater amount of polyester in these formulations had a remarkable effect in controlling the drug release rate. This faster release of resveratrol from PHBV microparticles can also be related to their porous surface previously observed by SEM. In general, microparticle studies have showed that the drug release rate is faster for higher-porosity materials [41].

Regarding the dissolution efficiency (DE), microparticles decreased this value extensively. Whereas the pure drug presented a DE of $96.2 \%$ along 720 minutes, PHBV microparticles showed DE of 73.3\% (M1R5), 78.6\% (M1R10), and 88.9\% (M1R20). For PCL microparticles, DE of 52.2, 78.0, and $85.0 \%$ was obtained for M2R5, M2R10, and M2R20, respectively. Previous papers reported that a high DE was verified for pharmaceutical dosage forms of immediate release while a lower value was indicative of a controlled release behavior $[46,47]$.

The release profiles were fitted to mathematical models, and the selection of the best model considered the correlation coefficient $(r)$, the model selection criteria (MSC), and the graphic adjustment. Resveratrol and PHBV/PCL microparticles were better fitted to the biexponential equation (Table 4) than other models. The burst-release apparent rate constant $(\alpha)$ and the slow-release apparent rate constant $(\beta)$ for resveratrol and PHBV/PCL microparticles are reported in Table 4.

These results demonstrated that PHBV/PCL microparticles reduced the drug dissolution rate, nevertheless without changing its release model. The first stage of release was initially rapid (burst release) whereas the second stage of release was slow (controlled release). The burst release can help to reach the effective concentration of resveratrol rapidly in plasma, whereas the controlled release would maintain the effective concentration of drug in plasma for a long time [22]. Moreover the poor bioavailability of resveratrol due to its rapid metabolism, including its conjugation with sulfate in the intestinal mucosa, and elimination could be partially avoided by microencapsulation, thus prolonging its biological half-time in vivo.

Concerning the mathematical modeling fitting the Korsmeyer-Peppas model, PHBV microparticles showed $n$ values of 1.23 (M1R5), 0.89 (M1R10), and 1.28 (M1R20). For PCL microparticles, $n$ values of $0.65,0.57$, and 0.73 were obtained for M2R5, M2R10, and M2R20, respectively. PHBV microparticles presented values of $n$ greater than 0.85 indicating that the release mechanism is governed by erosion [27]. Considering that PHBV is an aqueousinsoluble polymer, the process can occur by sequential 
TABLE 4: Release data obtained by fitting the dissolution profiles of pure resveratrol and PHBV/PCL microparticles to the biexponential equation.

\begin{tabular}{lcccc}
\hline Material & & \multicolumn{3}{c}{ Biexponential model } \\
& MSC & $R$ & $\alpha\left(\min ^{-1}\right)$ & 0.9902 \\
Resveratrol & 5.45 & 0.9988 & 0.0357 & 0.8262 \\
M1R5 & 5.30 & 0.9984 & 0.0082 & 0.0054 \\
M1R10 & 5.23 & 0.9982 & 0.0360 & 0.0082 \\
M1R20 & 4.26 & 0.9953 & 0.0693 & 0.0042 \\
M2R5 & 2.18 & 0.9616 & 0.0465 & 0.0014 \\
M2R10 & 4.32 & 0.9956 & 0.0363 & 0.0044 \\
M2R20 & 4.18 & 0.9949 & & 0.0066 \\
\hline
\end{tabular}

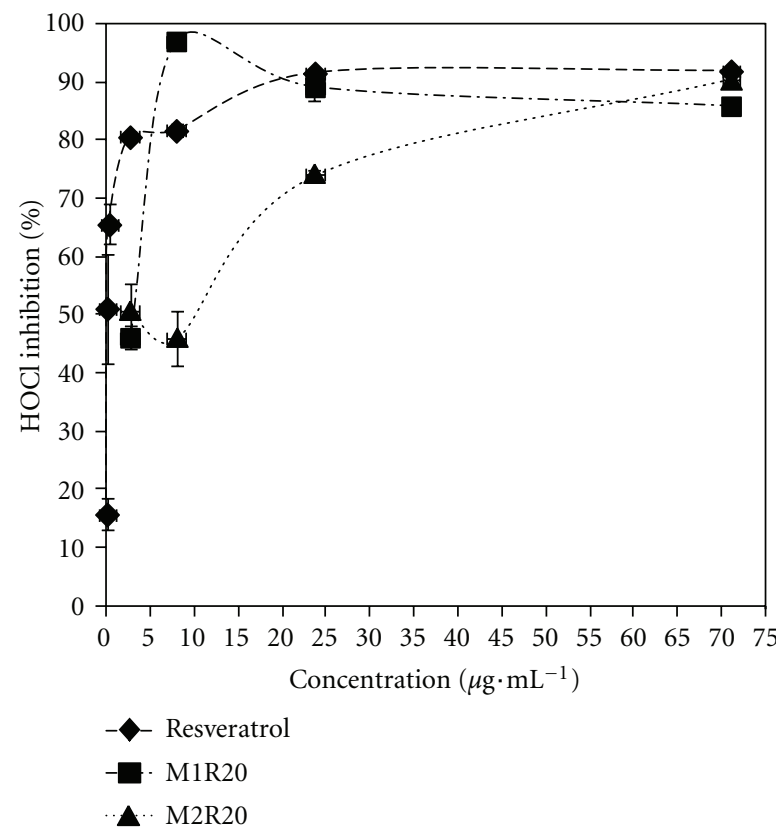

(a)

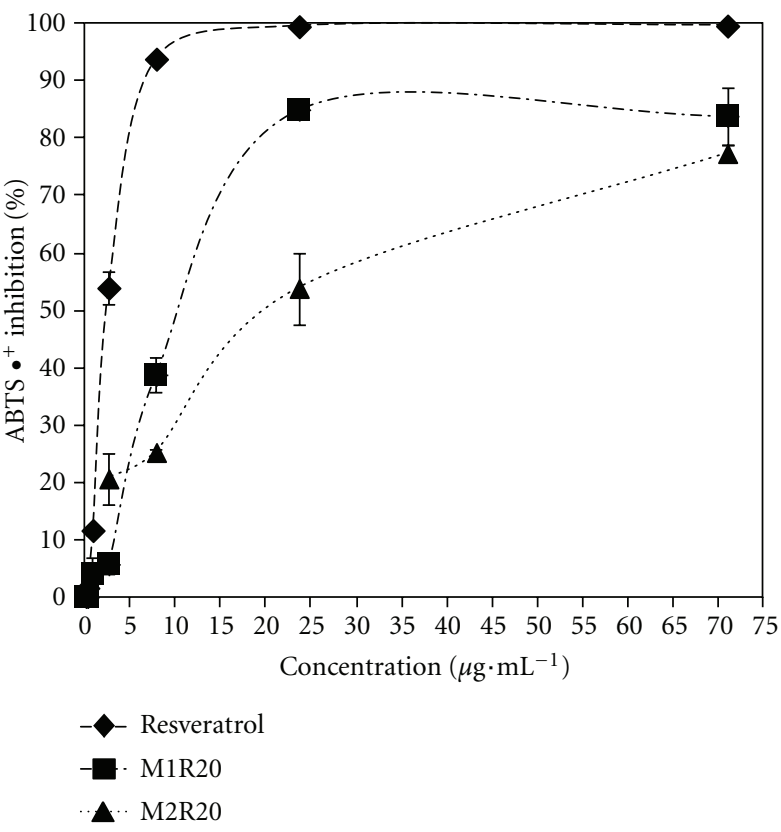

(b)

FIgURE 9: Antioxidant effect of pure resveratrol, and PHBV/PCL microparticles by HOCl- (a) and ABTS ${ }^{\bullet+}$ (b) scavenging activity.

stages of entrance of water and drug release. Otherwise PCL microparticles revealed values of $n$ between 0.43 and 0.85 . These intermediate values are related to an anomalous behavior, a non-Fickian kinetics corresponding to the superposition of diffusion and erosion phenomena [27].

3.8. Antioxidant Potential. In order to explore whether the microencapsulation has influence on antioxidant capacity of resveratrol, $\mathrm{HOCl}$-scavenging activity and ABTS radical cation discoloration assay of pure resveratrol and resveratrolloaded microparticles at the same drug concentrations were compared.

The HOCl-scavenging potential of pure resveratrol and PHBV/PCL microparticles is presented in Figure 9(a). Resveratrol $\left(\mathrm{IC}_{50}=0.08 \mu \mathrm{g} \cdot \mathrm{mL}^{-1}\right)$ and $\mathrm{M} 1 \mathrm{R} 20\left(\mathrm{IC}_{50}=\right.$ $3.03 \mu \mathrm{g} \cdot \mathrm{mL}^{-1}$ ) showed higher effect on $\mathrm{HOCl}$ scavenging activity, and were followed by M2R20 $\left(\mathrm{IC}_{50}=9.84 \mu \mathrm{g} \cdot \mathrm{mL}^{-1}\right)$.
In biological systems, $\mathrm{HOCl}$ is the most toxic and abundant oxidizing agent produced by polymorphonuclear neutrophils. It can also attack important biological molecules and generate other harmful ROS.

The results for ABTS radical cation discoloration test are shown in Figure 9(b). Considering ABTS $^{\bullet+}$ - scavenging potential, a higher activity was obtained for resveratrol $\left(\mathrm{IC}_{50}=\right.$ $\left.2.79 \mu \mathrm{g} \cdot \mathrm{mL}^{-1}\right)$ and M1R20 $\left(\mathrm{IC}_{50}=11.85 \mu \mathrm{g} \cdot \mathrm{mL}^{-1}\right)$. An $\mathrm{IC}_{50}$ value of $21.50 \mu \mathrm{g} \cdot \mathrm{mL}^{-1}$ was observed for formulation M2R20. This assay is widely used for screening the antioxidant properties of different compounds and reflects their capacity to donate electrons or hydrogen for inactivating this radical. In both assays, the unloaded microparticles presented a negligible antioxidant effect.

Regarding the studied concentrations, pure drug and resveratrol-loaded PHBV/PCL microparticles showed different efficiencies in scavenging capacity. Although the results 
indicated a lower antioxidant activity for resveratrol from PHBV/PCL microparticles, it is important to remember that scavenging assays were performed about $1 \mathrm{~h}$ after preparation of aqueous solutions under test, and resveratrol entrapped into polyester microparticles was not completely available to react with oxidizing agents. Therefore PHBV/PCL microparticles have an antioxidant effect even more promising for pharmaceutical purposes than pure drug because of their potential as a controlled-release carrier for prolonging in vivo bioavailability of resveratrol. In Despite its high antioxidant activity, pure resveratrol can present a less appropriate behavior biologically due to its rapid metabolism and elimination.

Morphology of PHBV/PCL microparticles and drug dissolution rate are also strongly related to these antioxidant activities. PHBV microparticles had porous surface which can provide a faster release of resveratrol as compared to PCL microparticles. This porous aspect can also permit a better access of oxidizing species to the resveratrol entrapped into PBHV microparticles. These antioxidant values are in accordance to the in vitro drug release profiles, since PCL microparticles revealed the slower dissolution rate.

Different data were previously reported for inclusion complexes between trans-resveratrol and $\beta$-cyclodextrin or hydroxypropyl- $\beta$-cyclodextrin that showed minor differences on scavenging capacity against an artificial oxidant, $\mathrm{DPPH}^{\bullet}[19]$. Otherwise the scavenging activity of resveratrol was reduced when lipid emulsion and aqueous micelle system were prepared [34].

Thus, it is possible to suggest that the resveratrol-loaded PHBV/PCL microparticles offer a feasible system to control resveratrol release as result of keeping its antioxidant effect.

3.9. Erythrocyte Hemolysis Assay. Hemolysis assay is a fast, efficient, simple, and low-cost procedure to investigate the cytotoxicity of micro-/nanoparticles on erythrocytes membrane by spectrophotometric measurement of the released hemoglobin [48]. The obtained results were presented in Figure 10. Regarding the hemolysis values, pure resveratrol and PHBV/PCL microparticles showed no significant differences to blank $(P>0.05)$. These data support that pure drug and PHBV/PCL microparticles particularly have compatibility with erythrocytes. A statistically significant difference was only observed between resveratrol and formulation M1R0 $(P=0.0467)$.

According to the literature, resveratrol exhibited no hemolytic effect to human red blood cells up to $100 \mu \mathrm{g} \cdot \mathrm{mL}^{-1}$ of concentration [49]. However no previous paper performed the erythrocyte hemolysis assay of resveratrolloaded and resveratrol-unloaded PHBV/PCL microparticles. Therefore this cytotoxicity assay results demonstrate that the obtained polyester microparticles have no hemolytic properties on human red blood cells which indicate their potential for pharmaceutical and biotechnological applications.

\section{Conclusion}

Polyester microparticles containing resveratrol were successfully prepared by simple emulsion/solvent evaporation.

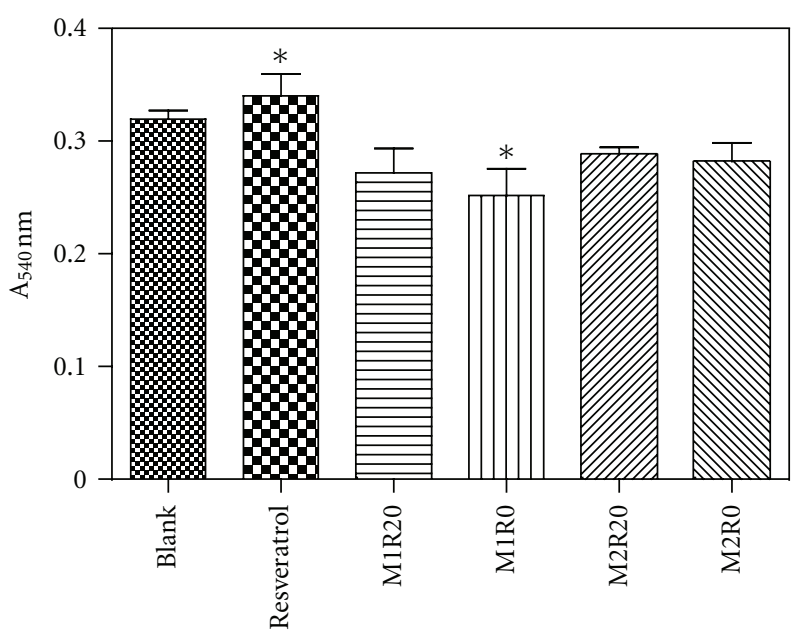

FIGURE 10: Absorbance values resulting from the released hemoglobin in erythrocyte hemolysis assay for blank, pure resveratrol, and PHBV/PCL microparticles. The asterisk indicates statistically significant difference $(P=0.0467)$.

High drug-loading efficiencies were obtained for PHBV/PCL microparticles. Morphological data played a crucial role in evaluating the drug release. Fourier-transformed infrared spectra indicated no chemical bond between resveratrol and polymers. X-ray powder diffraction patterns and differential scanning calorimetry analyses demonstrated that microencapsulation led to a drug amorphization. PHBV/PCL microparticles provided a substantial decrease of dissolution rate of resveratrol without changing its biexponential release model. The antioxidant potential of resveratrol entrapped into PHBV/PCL microparticles was kept, but was dependent on the microparticle morphology and dissolution profile. PHBV/PCL microparticles showed no cytotoxic effect on red blood cells. These results support an experimental basis for the use of resveratrol-loaded PHBV/PCL microparticles as a feasible oral drug delivery carrier for controlled release of resveratrol, being an attractive alternative in chronic diseases prevention.

\section{Acknowledgments}

The authors thank the Postgraduate Program in Pharmaceutical Sciences of State University of Ponta Grossa for providing infrastructure, constant support, and encouragements. The authors have no direct relation or financial involvement with any commercial organization with interest in the subject or materials discussed in this paper.

\section{References}

[1] Ö. Karacay, A. Sepici-Dincel, D. Karcaaltincaba et al., "A quantitative evaluation of total antioxidant status and oxidative stress markers in preeclampsia and gestational diabetic patients in 24-36 weeks of gestation," Diabetes Research and Clinical Practice, vol. 89, no. 3, pp. 231-238, 2010.

[2] K. B. Pandey and S. I. Rizvi, "Resveratrol may protect plasma proteins from oxidation under conditions of oxidative stress 
in vitro," Journal of the Brazilian Chemical Society, vol. 21, no. 5, pp. 909-913, 2010.

[3] K. Premkumar and C. L. Bowlus, "Ascorbic acid reduces the frequency of iron induced micronuclei in bone marrow cells of mice," Mutation Research-Genetic Toxicology and Environmental Mutagenesis, vol. 542, no. 1-2, pp. 99-103, 2003.

[4] A. L. B. S. Barreiros, J. M. David, and J. P. David, "Estresse oxidativo: relação entre geração de espécies reativas e defesa do organismo," Quimica Nova, vol. 29, no. 1, pp. 113-123, 2006.

[5] G. Shi, L. Rao, H. Yu, H. Xiang, H. Yang, and R. Ji, "Stabilization and encapsulation of photosensitive resveratrol within yeast cell," International Journal of Pharmaceutics, vol. 349, no. 1-2, pp. 83-93, 2008.

[6] G. D. Norata, P. Marchesi, S. Passamonti, A. Pirillo, F. Violi, and A. L. Catapano, "Anti-inflammatory and anti-atherogenic effects of cathechin, caffeic acid and trans-resveratrol in apolipoprotein E deficient mice," Atherosclerosis, vol. 191, no. 2, pp. 265-271, 2007.

[7] N. S. Shenouda, C. Zhou, J. D. Browning et al., "Phytoestrogens in common herbs regulate prostate cancer cell growth in vitro," Nutrition and Cancer, vol. 49, no. 2, pp. 200-208, 2004.

[8] S. Jarolim, J. Millen, G. Heeren, P. Laun, D. S. Goldfarb, and M. Breitenbach, "A novel assay for replicative lifespan in Saccharomyces cerevisiae," FEMS Yeast Research, vol. 5, no. 2, pp. 169-177, 2004.

[9] G. M. Pacifici, "Inhibition of human liver and duodenum sulfotransferases by drugs and dietary chemicals: a review of the literature," International Journal of Clinical Pharmacology and Therapeutics, vol. 42, no. 9, pp. 488-495, 2004.

[10] R. E. King, J. A. Bomser, and D. B. Min, "Bioactivity of resveratrol," Comprehensive Reviews in Food Science and Food Safety, vol. 5, no. 3, pp. 65-70, 2006.

[11] S. Das and K. Y. Ng, "Resveratrol-loaded calcium-pectinate beads: effects of formulation parameters on drug release and bead characteristics," Journal of Pharmaceutical Sciences, vol. 99, no. 2, pp. 840-860, 2010.

[12] C. Lucas-Abellán, I. Fortea, J. M. López-Nicolás, and E. Núñez-Delicado, "Cyclodextrins as resveratrol carrier system," Food Chemistry, vol. 104, no. 1, pp. 39-44, 2007.

[13] J. A. Baur and D. A. Sinclair, "Therapeutic potential of resveratrol: the in vivo evidence," Nature Reviews Drug Discovery, vol. 5, no. 6, pp. 493-506, 2006.

[14] M. Jang, L. Cai, G. O. Udeani et al., "Cancer chemopreventive activity of resveratrol, a natural product derived from grapes," Science, vol. 275, no. 5297, pp. 218-220, 1997.

[15] D. Nemen and E. Lemos-Senna, "Preparação e caracterização de suspensões coloidais de nanocarreadores lipídicos contendo resveratrol destinados á administração cutânea," Química Nova, vol. 34, no. 3, pp. 408-413, 2011.

[16] B. K. Kim, J. S. Lee, J. K. Oh, and D. J. Park, "Preparation of resveratrol-loaded poly( $\varepsilon$-caprolactone) nanoparticles by oilin-water emulsion solvent evaporation method," Food Science and Biotechnology, vol. 18, no. 1, pp. 157-161, 2009.

[17] Z. Piñeiro, M. Palma, and C. G. Barroso, "Determination of trans-resveratrol in grapes by pressurised liquid extraction and fast high-performance liquid chromatography," Journal of Chromatography A, vol. 1110, no. 1-2, pp. 61-65, 2006.

[18] B. C. Trela and A. L. Waterhouse, "Resveratrol: isomeric molar absorptivities and stability," Journal of Agricultural and Food Chemistry, vol. 44, no. 5, pp. 1253-1257, 1996.

[19] Z. Lu, B. Cheng, Y. Hu, Y. Zhang, and G. Zou, "Complexation of resveratrol with cyclodextrins: solubility and antioxidant activity," Food Chemistry, vol. 113, no. 1, pp. 17-20, 2009.
[20] R. L. Frozza, A. Bernardi, K. Paese et al., "Characterization of trans-resveratrol-loaded lipid-core nanocapsules and tissue distribution studies in rats," Journal of Biomedical Nanotechnology, vol. 6, no. 6, pp. 694-703, 2010.

[21] E. A. Oganesyan, I. I. Miroshnichenko, N. S. Vikhrieva, A. A. Lyashenko, and S. Y. Leshkov, "Use of nanoparticles to increase the systemic bioavailability of trans-resveratrol," Pharmaceutical Chemistry Journal, vol. 44, no. 2, pp. 25-27, 2010.

[22] H. Peng, H. Xiong, J. Li et al., "Vanillin cross-linked chitosan microspheres for controlled release of resveratrol," Food Chemistry, vol. 121, no. 1, pp. 23-28, 2010.

[23] M. K. Riekes, F. M. Barboza, D. D. Vecchia et al., "Evaluation of oral carvedilol microparticles prepared by simple emulsion technique using poly(3-hydroxybutyrate-co-3hydroxyvalerate) and polycaprolactone as polymers," Materials Science and Engineering C, vol. 31, no. 5, pp. 962-968, 2011.

[24] ICH-Harmonised Tripartity Guideline, Validation of Analytical Procedures: Methodology, International Federation of Pharmaceutical Manufacturers \& Associations, Geneva, Switzerland, 2005.

[25] K. A. Khan, “The concept of dissolution efficiency," Journal of Pharmacy and Pharmacology, vol. 27, no. 1, pp. 48-49, 1975.

[26] R. C. R. Beck, A. R. Pohlmann, E. V. Benvenutti, T. D. Costa, and S. S. Guterres, "Nanostructure-coated diclofenac-loaded microparticles: preparation, morphological characterization, in vitro release and in vivo gastrointestinal tolerance," Journal of the Brazilian Chemical Society, vol. 16, no. 6, pp. 1233-1240, 2005.

[27] J. Siepmann and N. A. Peppas, "Modeling of drug release from delivery systems based on hydroxypropyl methylcellulose (HPMC)," Advanced Drug Delivery Reviews, vol. 48, no. 2-3, pp. 139-157, 2001.

[28] J. M. Dypbukt, C. Bishop, W. M. Brooks, B. Thong, H. Eriksson, and A. J. Kettle, "A sensitive and selective assay for chloramine production by myeloperoxidase," Free Radical Biology and Medicine, vol. 39, no. 11, pp. 1468-1477, 2005.

[29] R. Re, N. Pellegrini, A. Proteggente, A. Pannala, M. Yang, and C. Rice-Evans, "Antioxidant activity applying an improved ABTS radical cation decolorization assay," Free Radical Biology and Medicine, vol. 26, no. 9-10, pp. 1231-1237, 1999.

[30] S. Li, G. C. Irvin, B. Simmons et al., "Structured materials syntheses in a self-assembled surfactant mesophase," Colloids and Surfaces A, vol. 174, no. 1-2, pp. 275-281, 2000.

[31] C. D. Hapner, P. Deuster, and Y. Chen, "Inhibition of oxidative hemolysis by quercetin, but not other antioxidants," ChemicoBiological Interactions, vol. 186, no. 3, pp. 275-279, 2010.

[32] A. Banerjee, A. Kunwar, B. Mishra, and K. I. Priyadarsini, "Concentration dependent antioxidant/pro-oxidant activity of curcumin. Studies from AAPH induced hemolysis of RBCs," Chemico-Biological Interactions, vol. 174, no. 2, pp. 134-139, 2008.

[33] C. Bosquillon, P. G. Rouxhet, F. Ahimou et al., "Aerosolization properties, surface composition and physical state of spraydried protein powders," Journal of Controlled Release, vol. 99, no. 3, pp. 357-367, 2004.

[34] C. F. Hung, C. L. Fang, M. H. Liao, and J. Y. Fang, "The effect of oil components on the physicochemical properties and drug delivery of emulsions: tocol emulsion versus lipid emulsion," International Journal of Pharmaceutics, vol. 335, no. 1-2, pp. 193-202, 2007.

[35] M. Maghsoodi, "Physicomechanical properties of naproxenloaded microparticles prepared from eudragit L100," American Association of Pharmaceutical Scientists, vol. 10, no. 1, pp. 120-128, 2009. 
[36] P. V. Farago, R. P. Raffin, A. R. Pohlmann, S. S. Guterres, and S. F. Zawadzki, "Physicochemical characterization of a hydrophilic model drug-loaded PHBV microparticles obtained by the double emulsion/solvent evaporation technique," Journal of the Brazilian Chemical Society, vol. 19, no. 7, pp. 1298-1305, 2008.

[37] M. A. T. Duarte, R. G. Hugen, E. S. Martins, A. P. T. Pezzin, and S. H. Pezzin, "Thermal and mechanical behavior of injection molded poly(3-hydroxybutyrate/poly $(\varepsilon-$ caprolactone) blends," Materials Research, vol. 9, no. 1, pp. 2527, 2006.

[38] H. K. Stulzer, M. A. S. Silva, D. Fernandes, and J. Assreuy, "Development of controlled release captopril granules coated with ethylcellulose and methylcellulose by fluid bed dryer," Drug Delivery, vol. 15, no. 1, pp. 11-18, 2008.

[39] M. P. Desai, V. Labhasetwar, G. L. Amidon, and R. J. Levy, "Gastrointestinal uptake of biodegradable microparticles: effect of particle size," Pharmaceutical Research, vol. 13, no. 12, pp. 1838-1845, 1996.

[40] N. Y. K. Chew and H. K. Chan, "Effect of powder polydispersity on aerosol generation," Journal of Pharmacy and Pharmaceutical Sciences, vol. 5, no. 2, pp. 162-168, 2002.

[41] F. S. Poletto, E. Jager, M. I. Ré, S. S. Guterres, and A. R. Pohlmann, "Rate-modulating PHBHV/PCL microparticles containing weak acid model drugs," International Journal of Pharmaceutics, vol. 345, no. 1-2, pp. 70-80, 2007.

[42] K. A. Ansari, P. R. Vavia, F. Trotta, and R. Cavalli, "Cyclodextrin-based nanosponges for delivery of resveratrol: in vitro characterisation, stability, cytotoxicity and permeation study," American Association of Pharmaceutical Scientists, vol. 12, no. 1, pp. 279-286, 2011.

[43] H. K. Stulzer, M. P. Tagliari, A. L. Parize, M. A. S. Silva, and M. C. M. Laranjeira, "Evaluation of cross-linked chitosan microparticles containing acyclovir obtained by spraydrying," Materials Science and Engineering C, vol. 29, no. 2, pp. 387-392, 2009.

[44] S. Kim, W. K. Ng, Y. Dong, S. Das, and R. B. H. Tan, "Preparation and physicochemical characterization of trans-resveratrol nanoparticles by temperature-controlled antisolvent precipitation," Journal of Food Engineering, vol. 108, no. 1, pp. 37-42, 2012.

[45] X. Sun, Y. Shao, and W. Yan, "Measurement and correlation of solubilities of trans-resveratrol in ethanol+water and acetone+water mixed solvents at different temperatures," Journal of Chemical and Engineering Data, vol. 53, no. 11, pp. 25622566, 2008.

[46] K. A. Fortunato, M. M. Doile, I. C. Schmücker, S. K. Schucko, M. A. S. Silva, and P. O. Rodrigues, "Influência da complexação $\operatorname{com} \beta$-ciclodextrina sobre a liberação do acetato de dexametasona a partir de matrizes hidrofílicas de hidroxipropilmetilcelulose (HPMC) e polioxetileno (PEO)," Latin American Journal of Pharmacy, vol. 26, no. 4, pp. 513-521, 2007.

[47] R. P. Raffin, L. M. Colomé, A. R. Pohlmann, and S. S. Guterres, "Preparation, characterization, and in vivo anti-ulcer evaluation of pantoprazole-loaded microparticles," European Journal of Pharmaceutics and Biopharmaceutics, vol. 63, no. 2, pp. 198204, 2006.

[48] L. F. Cótica, V. F. Freitas, G. S. Dias et al., "Simple and facile approach to synthesize magnetite nanoparticles and assessment of their effects on blood cells," Journal of Magnetism and Magnetic Materials, vol. 324, no. 4, pp. 559-563, 2012.
[49] H. J. Jung, Y. B. Seu, and D. G. Lee, "Candicidal action of resveratrol isolated from grapes on human pathogenic yeast C. albicans," Journal of Microbiology and Biotechnology, vol. 17, no. 8, pp. 1324-1329, 2007. 

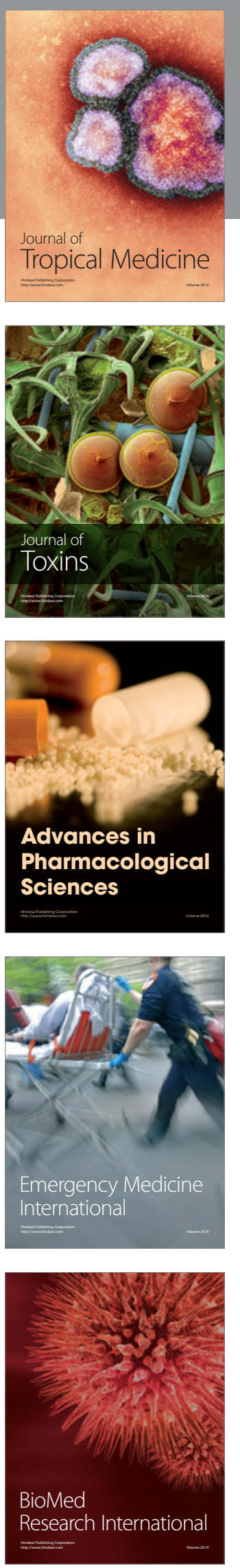
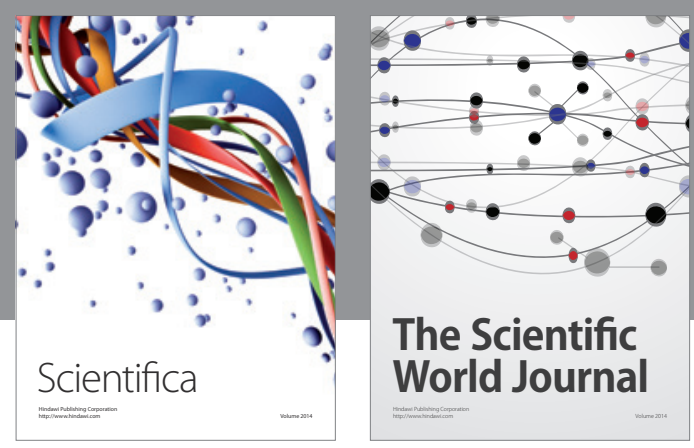

The Scientific World Journal
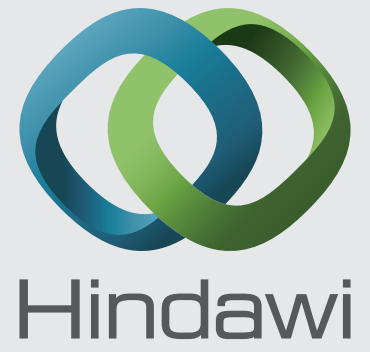

Submit your manuscripts at

http://www.hindawi.com
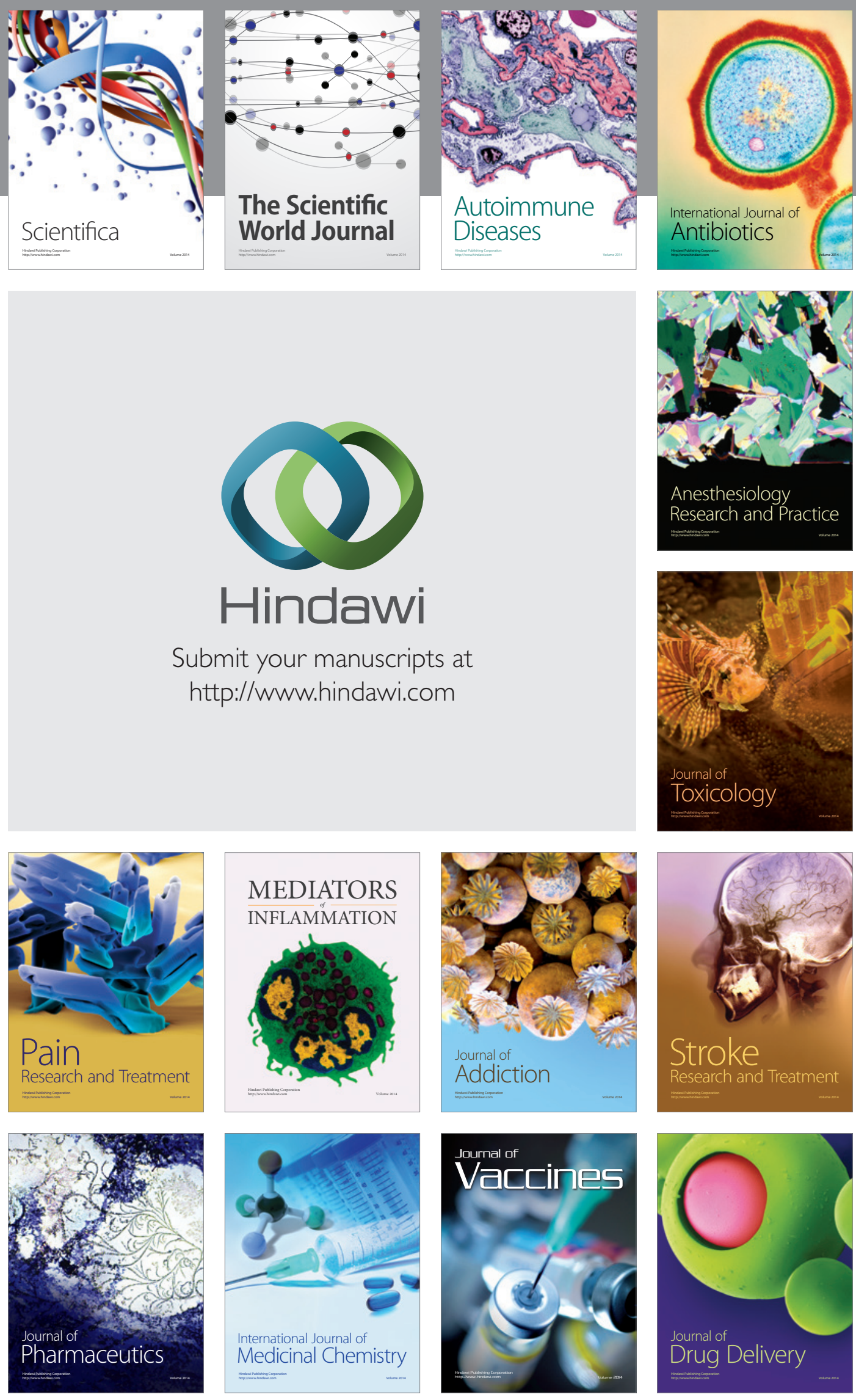